\title{
THEORETICAL INVESTIGATION OF A CONIC-HELICAL LOOSENER FOR FERTILIZER APPLYING MACHINE
}

\author{
Sayakhat Nukeshev, Dzhadyger Eskhozhin, Dimitar Karaivanov, Kairat Eskhozhin, Aigul Balabekova, \\ Ziada Zhaksylykova, Yevgeniy Zolotukhin
}

Original scientific paper

The paper reveals that the available facilities of granular fertilizer applying do not completely meet the technical requirements. In order to ensure stable and reliable dosing of fertilizers it is necessary to destroy the arch obtained above the hopper outlet and to provide forced feeding of the material (fertilizer) to the feeder (measuring device). The goal of the study is selection of optimum parameters of the fertilizer applying machine conic-helical loosener. The theoretical researches carried out allow to establish the relation between the motion (speed and displacement) of the material (fertilizer) elementary particles along the coils of the springs and the loosener design and technological parameters (the angle between the generant and axis-cones, the helix angle of spring coils, the cone base radius, the coefficients of external and internal friction, the angular speed). By varying each one of the parameters their optimum combination could be selected depending on the accepted loosener efficiency criterion.

Keywords: applying machine; feeder; granular fertilizer; loosener

Teorijsko ispitivanje konično-helikoidnog rasipača stroja za umjetno gnojivo

Izvorni znanstveni članak

Rad pokazuje da postojeći uređaji za rasipanje umjetnog gnojiva u granulama u potpunosti ne zadovoljavaju tehničke potrebe. Kako bi se osiguralo postojano i pouzdano doziranje gnojiva potrebno je dokinuti luk iznad izlaza iz lijevka i osigurati prisilni dovod materijala (gnojiva) u napojni (mjerni) uređaj. Cilj istraživanja je odabir optimalnih parametara konično-helikoidnog rasipača uređaja za rasipanje umjetnog gnojiva. Provedena teorijska istraživanja omogućuju uspostavu odnosa između gibanja (brzina i istiskivanje) elementarnih čestica materijala (gnojiva) duž opruga zavojnice i konstrukcije i tehnoloških parametara rasipača (kut između generant i konusne osovine, kut uspona spirale opruga zavojnice, polumjer baze konusa, faktor vanjskog $\mathrm{i}$ unutarnjeg trenja, kutna brzina). Variranjem svakog pojedinog parametra može se izabrati njihova optimalna kombinacija ovisno o prihvaćenom kriteriju učinkovitosti rasipača.

Ključne riječi: napojni uređaj; rasipač; stroj za umjetno gnojivo; uređaj za rasipanje umjetnog gnojiva u granulama

\section{Introduction}

The available granular fertilizer applying facilities do not completely meet the technical requirements. The main reason for the low quality of fertilizer dosing is the formation of an arch above the hopper outlet. That is connected with the complex physical-mechanical properties of the granular fertilizers, which sharply change depending on the moisture content. With moisture increase some types of fertilizers transform in plastic, clay like state while others form lumps of different size piling up around the outlet. Along with that, arch formation could be caused by shortcomings in the feeder design, hopper configuration, shape and dimensions of the outlet, etc. $[1 \div 4]$. As a result of the cavity and arch formation in the hopper the technological process of fertilizer dosing is disturbed which leads to its irregular applying and bad yield [5].

The disturbance of the uniform dosing reflects particularly negatively in the machines applying the fertilizer in the soil immediately next to the roots of the plants $[6 \div 8]$. The effectiveness of these machines depends to a great extent on the precision of fertilizer dosing.

In order to have stable and reliable dosing of hygroscopic granular fertilizers it is necessary to destroy the arches and forcedly feed the material to the feeder. In spite of the available great quantity of design and research attempts to resolve this problem it continues to be the narrow point in the dosing process, requires thorough theoretical and experimental study, development of promising versatile constructions and for this reason it is topical.
Publication [9] suggests original solution of removing the static zones in the hopper, preventing fertilizer transfer in one direction and improving the dosing uniformity (of fertilizer). That is achieved by setting up two rotating conic-helical springs of common base on a shaft in the hopper above the feeder.

The purpose of the present study is development of a method for determination of the optimum parameters for the suggested in [9] original construction of conic-helical loosener for granular fertilizer applying machine.

\section{Design solution}

The essence of the suggested in [9] engineering solution is presented in Fig. 1. In the bottom part of the hopper 1 there are outlet 2 , feeder 3 , transmitter (feeding tube) 4 and shaft 5 , on which there are fixed conic-helical springs 6 with their bases in contact, which loosen the material. The bases of the springs 6 are fixed to the shaft 5 and their tips are loosely (movably) assembled that permits to freely contract and expand. The coils of the two springs are in opposite directions. Transmission 7 drives the shaft 5 . The directions of the coils of the right and left parts of the conic spring 6 are opposite.

During operation of the loosener, the material (fertilizer) presses and contracts the spring coils. Upon reaching a definite force in the springs they sharply expand and affect the material by impact loosening it and breaking the lumps. 


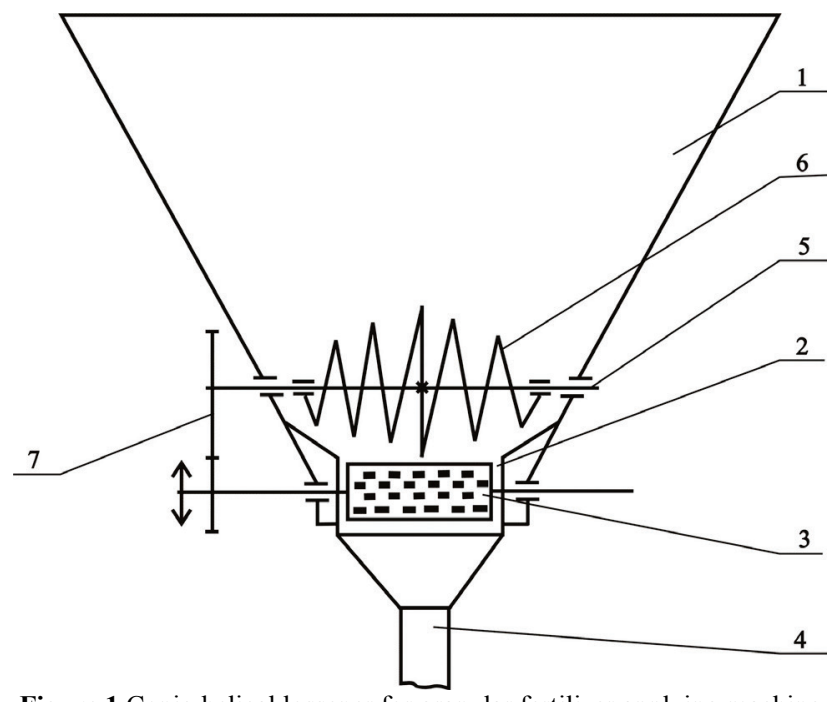

Figure 1 Conic-helical lossener for granular fertilizer applying machine [9]

\section{Computing model}

In the theoretical examination of the material interaction with the conic-helical loosener we consider an elementary volume $M$ of the material standing on the coil of conic-helical spring which rotates around horizontal axis at angular speed $\omega$ (Fig. 2) [10]. The following forces act on this elementary volume:

$G$ - the force of the material particle (elementary volume) weight;

$N$ - the coil normal reaction on the elementary volume (perpendicular to the cone surface);

$F=f \cdot N$ - the force of friction between the material in the spring coils;

$N_{1}$ - the environment normal reaction;

$F_{1}=f_{1} \cdot N_{1}$ - the force of friction between the elementary volume and environment;

$R_{c}=m \cdot \omega^{2} \cdot r$ - centrifugal force of the material in elementary volume;

$R_{C o}=2 m \cdot \omega \cdot \dot{x}$ - Coriolis force (opposite to Coriolis acceleration). It is perpendicular to the plane of the vectors of the relative and transportation velocities in direction in which the rotation of the second towards the first would be realized in clockwise direction.

In the initial moment the elementary volume is in position $M_{0}$. After time $t$, as a result of the transportation movement, it goes to position $M_{1}$. But making relative movement in relation to the spring coil, in absolute movement the elementary volume occupies position $\mathrm{M}^{\prime}$. For greater clarity, we shall transfer it to the middle of the loosener, in point $\mathrm{M}$.

For the purposes of the theoretical examination the following angles should be known:

$\omega t$ - the angle which determines the position of the elementary volume for time $t$;

$\alpha$ - the helix angle of the spring;

$\xi$ - the angle between the generant and the spring cone axis (cone generant angle).

The axes of the coordinate system are located in the following way:

$x$ - along the spreading of the spring coil $y$ - along the binormal passing through the centre of the cross-section circumference;

$z$-along the main normal, perpendicular to the helix.
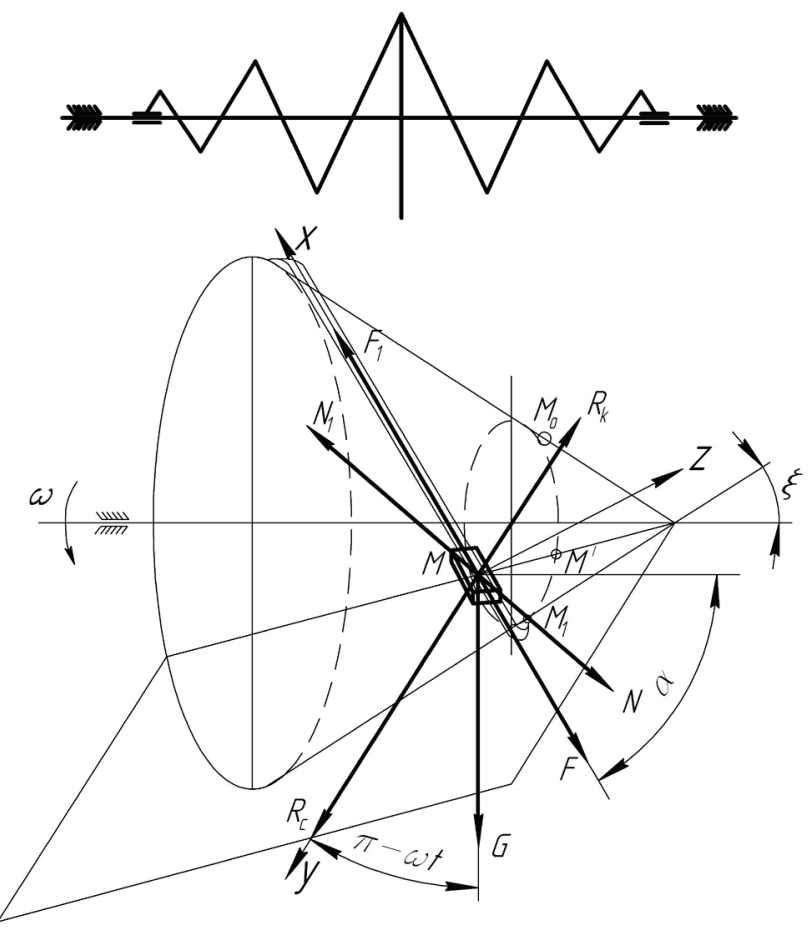

Figure 2 Forces acting on the elementary volume

The equations of equilibrium of forces acting on the elementary volume along the three axes are:

$$
\begin{aligned}
m x^{\prime \prime}= & F-F_{1}-N \cdot \sin \xi \cdot \cos \alpha+N_{1} \cdot \sin \xi \cdot \cos \alpha- \\
& -G \cdot \sin (\pi-\omega t) \cdot \cos \left(\frac{\pi}{2}-\alpha\right), \\
m y^{\prime \prime}= & R_{c}-R_{C o}+N \cdot \cos \xi-N_{1} \cdot \cos \xi+G \cdot \cos (\pi-\omega t), \\
m z^{\prime \prime}= & N \cdot \sin \xi \cdot \cos \left(\frac{\pi}{2}-\alpha\right)-N \cdot \sin \xi \cdot \cos \left(\frac{\pi}{2}-\alpha\right)- \\
& -G \cdot \sin (\pi-\omega t) \cdot \cos \alpha, \\
m x^{\prime \prime}= & F-F_{1}-N \cdot \sin \xi \cdot \cos \alpha+N_{1} \cdot \sin \xi \cdot \cos \alpha- \\
& -G \cdot \sin \omega t \cdot \cos \alpha, \\
m y^{\prime \prime}= & R_{c}-R_{C o}+N \cdot \cos \xi-N_{1} \cdot \cos \xi+G \cdot \cos \omega t, \\
m z^{\prime \prime}= & N \cdot \sin \xi \cdot \sin \alpha-N \cdot \sin \xi \cdot \sin \alpha-G \cdot \sin \omega t \cdot \cos \alpha .
\end{aligned}
$$

After grouping the members with $N$ and $N_{1}$ it is obtained:

$m x^{\prime \prime}=\left(N_{1}-N\right) \sin \xi \cdot \cos \alpha-G \cdot \sin \omega t \cdot \sin \alpha-F+F_{1} ;$

$m y^{\prime \prime}=\left(N-N_{1}\right) \cos \xi-G \cdot \cos \omega t+R_{c}-R_{C o} ;$

$m z^{\prime \prime}=\left(N-N_{1}\right) \sin \xi \cdot \sin \alpha-G \cdot \sin \omega t \cdot \cos \alpha$.

From Eq. (2) we determine $N-N_{1}$

$\left(N-N_{1}\right)=\frac{1}{\cos \xi}\left(G \cdot \cos \omega t+R_{C o}-R_{c}\right)=G \frac{\sin \omega t}{\sin \xi \cdot \tan \alpha}$.

After equalizing the left sides of Eq. (3) we determine the dependence of the cone angle $\xi$ on the design and technological parameters 


$$
\begin{aligned}
& \frac{1}{\cos \xi}\left(G \cdot \cos \omega t+R_{C o}-R_{c}\right)=G \frac{\sin \omega t}{\sin \xi \cdot \tan \alpha} \\
& \tan \xi=\frac{g \cdot \sin \omega t}{\tan \alpha\left[g \cdot \cos \omega t+2 \omega \cdot \dot{x}-\omega^{2} \cdot r\right]}
\end{aligned}
$$

After replacement of Eq. (3) in the first equation of system Eq. (2) it is obtained

$$
\begin{aligned}
& m \ddot{x}=-G \frac{\sin \omega t}{\sin \xi \cdot \tan \alpha} \sin \xi \cdot \cos \alpha-G \cdot \sin \omega t \cdot \sin \alpha- \\
& -\frac{f}{\cos \xi}\left[G \cdot \cos \omega t+R_{C o}-R_{c}\right]+f_{1} \cdot N_{1} .
\end{aligned}
$$

After placing the known quantities in Eq. (5) and transformation we obtain

$$
\begin{aligned}
& m \ddot{x}=-m \cdot g \cdot \sin \omega t\left(\frac{\cos \alpha}{\tan \alpha}+\sin \alpha\right)-\frac{f \cdot m \cdot g}{\cos \xi} \cos \omega t- \\
& -\frac{f}{\cos \xi} 2 m \cdot \omega \cdot \dot{x}+\frac{f}{\cos \xi} m \cdot \omega^{2} \cdot r+f_{1} \cdot m,
\end{aligned}
$$

where it is assumed that $N_{1}$ can be commensurable with the action of column of $m g$ material on unit volume. However $m g=\rho V=\frac{m}{V} V=m \quad(\rho$ is the fertilizer bulk density).

$\mathrm{Or}$

$\ddot{x}+\frac{2 f \omega}{\cos \xi} \dot{x}=-\frac{g}{\sin \alpha} \sin \omega t-\frac{f \cdot g}{\cos \xi} \cos \omega t+$

$+\frac{1}{\cos \xi} f \cdot \omega^{2} \cdot r+f_{1}$.

The following designations are accepted

$$
\begin{aligned}
& \frac{2 f \cdot \omega}{\cos \xi}=b ; \\
& \frac{g}{\sin \alpha}=l ; \\
& \frac{f \cdot g}{\cos \xi}=m ; \\
& \frac{f \cdot \omega^{2} \cdot r}{\cos \xi}+f_{1}=n .
\end{aligned}
$$

Considering Eq. (8) equation (7) assumes the form

$$
\ddot{x}+b \cdot \dot{x}=n-m \cdot \cos \omega t-l \cdot \sin \omega t
$$

There is obtained an inhomogeneous differential equation of second order of constant coefficients.

The common solution of Eq. (9) is

$$
x=x_{0}+\bar{x},
$$

where $x_{0}$ is the solution of the homogeneous part and $\bar{x}$, the particular solution of the inhomogeneous equation.

\section{Solving the equations \\ 4.1 Solution of the homogeneous part}

Characteristic equation of the homogeneous part of Eq. (9) is

$k^{2}+b \cdot k=0$

The roots are equal $k_{1}=0$ and $k_{2}=-b$.

In this case the solution of Eq. (11) has the form

$x_{0}=C_{1}+C_{2} \cdot e^{-b t}$

The right hand side of the inhomogeneous Eq. (9) has a free member $n$. Therefore, the particular solution is looked for as the sum of two functions $f_{1}$ and $f_{2}$ :

$f_{1}=A \cdot \cos \omega t+B \cdot \sin \omega t$

$f_{2}=C \cdot t$.

In this case the particular solution of Eq. (9) has the form

$\bar{x}=A \cdot \cos \omega t+B \cdot \sin \omega t+C \cdot t$

On defining the first and second derivative of Eq.

$\vec{x}^{\prime}=-A \cdot \omega \cdot \sin \omega t+B \cdot \omega \cdot \cos \omega t+C ;$

$\vec{x}^{\prime \prime}=-A \cdot \omega^{2} \cdot \cos \omega t-B \cdot \omega^{2} \cdot \sin \omega t$.

and their replacement in Eq. (9) it is obtained

$-A \cdot \omega^{2} \cdot \cos \omega t-B \cdot \omega^{2} \cdot \sin \omega t+(-A \cdot b \cdot \omega \cdot \sin \omega t)+$

$+B \cdot b \cdot \omega \cdot \cos \omega t+C \cdot b=n-m \cdot \cos \omega t-l \cdot \sin \omega t$

which after grouping a part of the members of similar trigonometric functions in the left side acquires the form

$$
\begin{aligned}
& \left(-A \cdot \omega^{2}+B \cdot b \cdot \omega\right) \cos \omega t+ \\
& +\left(-B \cdot \omega^{2}-A \cdot b \cdot \omega\right) \sin \omega t+C \cdot b= \\
& =n-m \cdot \cos \omega t-l \cdot \sin \omega t .
\end{aligned}
$$

After equalization of the coefficients in front of the similar trigonometric functions and the free members of the right and left hand of side of Eq. (15)

$$
\left\{\begin{array}{c}
-A \cdot \omega^{2}+B \cdot b \cdot \omega=-m \\
-B \cdot \omega^{2}-A \cdot b \cdot \omega=-l \\
C \cdot b=n
\end{array},\left\{\begin{array}{c}
A=\frac{m+B \cdot b \cdot \omega}{\omega^{2}} \\
B=\frac{l-A \cdot b \cdot \omega}{\omega^{2}} \\
C=\frac{n}{b}
\end{array}\right.\right.
$$

we determine $A$ from the first equation of system (16)

$$
A=\frac{m \cdot \omega+b \cdot l}{\omega\left(\omega^{2}+b^{2}\right)}
$$


and from the second $-B$

$B=\frac{l \cdot \omega-b \cdot m}{\omega\left(\omega^{2}+b^{2}\right)}$

After replacement of Eq. (17) and Eq. (18) in Eq. (13) we obtain the particular solution of the initial equation (9)

$\bar{x}=\frac{1}{\omega\left(\omega^{2}+b^{2}\right)}[(m \cdot \omega+b \cdot l) \cos \omega t+$

$+(l \cdot \omega-b \cdot m) \sin \omega t]+\frac{n}{b} t$

\subsection{Differential equation common solution}

The common solution of the initial inhomogeneous differential equation of second order (9) is obtained after replacement in Eq. (10) of the homogeneous and particular solutions Eq. (12) and Eq. (19):

$x=C_{1}+C_{2} \cdot e^{-b t}+\frac{1}{\omega\left(\omega^{2}+b^{2}\right)}[(m \cdot \omega+b \cdot l) \cos \omega t+$

$+(l \cdot \omega-b \cdot m) \sin \omega t]+\frac{n}{b} t$

It is known by definition, that in the initial moment, at $t=0$, the relative coil motion and the relative speed are also equal to zero, i.e. $x=0 ; \dot{x}=0$.

The equalized to zero first derivative of Eq. (20) is

$\dot{x}=-C_{2} \cdot b \cdot e^{-b t}+\frac{(m \cdot \omega+b \cdot l) \omega}{\omega\left(\omega^{2}+b^{2}\right)}(-\sin \omega t)+$

$+\frac{(l \cdot \omega-b \cdot m) \omega}{\omega\left(\omega^{2}+b^{2}\right)} \cos \omega t+\frac{n}{b}=0$

$C_{2} \cdot b \cdot e^{-b t}=\frac{(l \cdot \omega-b \cdot m)}{\left(\omega^{2}+b^{2}\right)} \cos \omega t-\frac{(m \cdot \omega+b \cdot l)}{\left(\omega^{2}+b^{2}\right)} \sin \omega t+\frac{n}{b}$

At $t=0$ from Eq. (21) it is obtained

$C_{2}=\frac{1}{b}\left(\frac{n}{b}+\frac{l \cdot \omega-b \cdot m}{\omega^{2}+b^{2}}\right)$

Using (22), Eq. (20) is equalized to zero

$x=\frac{m \cdot \omega+b \cdot l}{\omega\left(\omega^{2}+b^{2}\right)} \cos \omega t+\frac{l \cdot \omega-b \cdot m}{\omega\left(\omega^{2}+b^{2}\right)} \sin \omega t+\frac{n}{b} t+C_{1}+$

$+\frac{e^{-b t}}{b}\left(\frac{n}{b}+\frac{l \cdot \omega-b \cdot m}{\omega^{2}+b^{2}}\right)=0$

At $t=0$ from Eq. (23) it is obtained

$C_{1}=\frac{1}{b}\left(\frac{n}{b}+\frac{l \cdot \omega-b \cdot m}{\omega^{2}+b^{2}}\right)-\frac{m \cdot \omega+b \cdot l}{\omega\left(\omega^{2}+b^{2}\right)}$
After replacement of $C_{1}$ and $C_{2}$ from Eq. (22) and Eq. (24) in the common solution Eq. (20) it is obtained

$x=\frac{1}{b}\left(\frac{n}{b}+\frac{l \cdot \omega-b \cdot m}{\omega^{2}+b^{2}}\right)\left(e^{-b t}-1\right)+\frac{1}{\omega\left(\omega^{2}+b^{2}\right)}$.

$\cdot[(m \cdot \omega+b \cdot l)(\cos \omega t-1)+(l \cdot \omega-b \cdot m) \sin \omega t]+\frac{n}{b} t$

There has been obtained the complete solution of the differential equation characterizing the interaction of the conic-helical loosener with the fertilizer.

By means of Eq. (8), equation (25) could be presented in an extended form

$$
\begin{aligned}
& x=\frac{q \cdot \cos \xi}{2 f \cdot \omega \cdot \sin \alpha}\left[\frac{\cos \xi}{2 f \cdot \omega}\left(\ell^{-\frac{2 f \omega t}{\cos \xi}}-1\right)+t\right]+ \\
& +\frac{\cos \xi\left(f \cdot \omega^{2} \cdot r+f_{1} \cdot \cos \xi-2 f^{2} \cdot \omega \cdot q\right)}{\omega^{2}\left(\cos ^{2} \xi+4 f^{2}\right)} . \\
& \cdot\left[\frac{\cos \xi}{2 f}\left(\ell^{-\frac{2 f \omega t}{\cos \xi}}-1\right)+\sin \omega t\right]+ \\
& +\frac{(\cos \omega t-1)}{\omega^{2}\left(\cos ^{2} \xi+4 f^{2}\right)} f\left[2 f \cdot \omega^{2} \cdot r+q \cdot \cos \xi\left(1+2 f_{1}\right)\right]
\end{aligned}
$$

\section{Analysis of the results}

In Eq. (21) and Eq. (26) there are established the dependences of the displacement and speed of the fertilizer elementary volume along the loosener helical spiral on the most important design and technological parameters - the angle between the cone generant and its axis (generant angle $\xi$, the helix angle $\alpha$, the helical surface radius $r$, the coefficients of internal and external friction and the loosener angular speed $\omega$. By varying each of these parameters one can select their optimum combination depending on the accepted criterion of loosener efficiency [10], [13].

Fig. 3 shows the dependences of fertilizer elementary volume displacement on the helix angle and on the angle between the cone generant and its axis. It is seen in them that the greatest effect on the elementary volume displacement along the loosener coil is produced by the helix angle. For instance, at cone generant angle $\xi=30^{\circ}$, the doubling of the helix angle (from $15^{\circ}$ to $30^{\circ}$ ) results in 2,3 times decrease of displacement, from $3,35 \mathrm{~mm}$ to $1,43 \mathrm{~mm}$ for time 0,5 seconds (Fig. 3). Besides, this dependence holds on for all values of cone generant angle, for the angular speed and for the radius on which the elementary volume lies on the cone.

For instance, calculations show that at angular speed of $1,0 \mathrm{~s}^{-1}$ the fertilizer displacement decreases from 3,41 $\mathrm{mm}$ to $1,47 \mathrm{~mm}$ for the values of $\alpha$ from $15^{\circ}$ to $30^{\circ}$. Similar dependence is also observed for fertilizer positioned on radius $r=0,03 \mathrm{~m}$ on the cone. The examined dependence could be explained by the fact that when the helix angle is increased the fertilizer transportation motion together with the coil decreases which results also in decrease of the relative displacement. 
The parameter next in importance that affects fertilizer displacement is the loosener angular speed. For fertilizer positioned at radius $r=0,03 \mathrm{~m}$ on the cone surface the double increase of the angular speed (from 2,0 to $4,0 \mathrm{~s}^{-1}$ ) leads to displacement decrease of 1,3 times from $4,46 \mathrm{~mm}$ to $3,46 \mathrm{~mm}$. This decrease is particularly intensive for small helix angles $\alpha$.

The decrease of the relative displacement with increase of the loosener angular speed is explained by the fact that in this case the slipping of the fertilizer particles on the loosener coils grows. Furthermore, the transportation displacement decreases which in the long run decreases the relative displacement, too.

On the basis of the above said we may conclude that the mechanisms of fertilizer particles displacement in all points of the loosener are similar.

Examining the dependences drawn, there could be selected variable loosener parameters to achieve optimum mixing of the fertilizer. Fig. 4 combines the dependences of fertilizer particles displacement on the helix angle and on the loosener angular speed. It is seen that uniform fertilizer stirring is achieved at helix angle of $14^{\circ}$ and angular speed of $3,1 \mathrm{~s}^{-1}$.

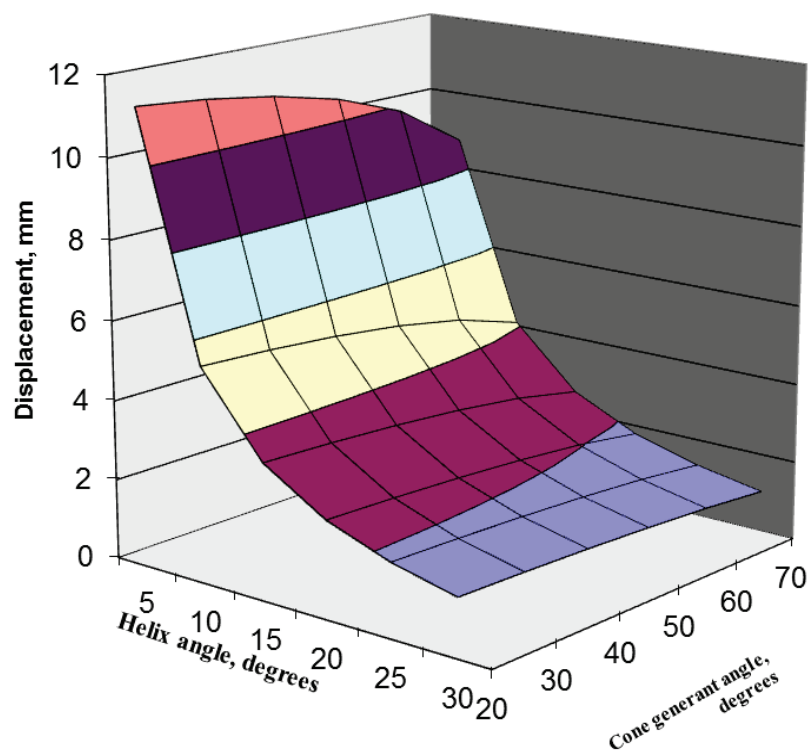

Figure 3 Dependence of the fertilizer elementary volume displacement on the helix angle and cone generant angle

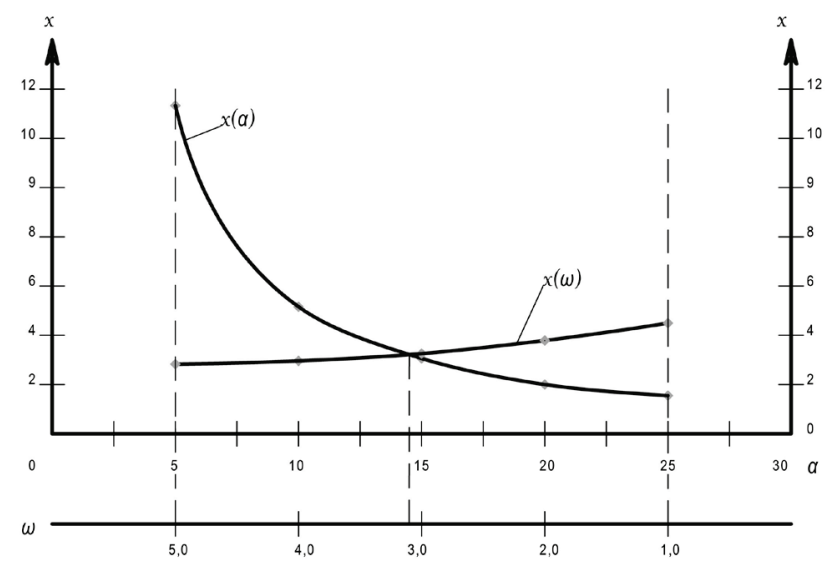

Figure 4 Common dependences of fertilizer displacement on the helix angle and the loosener angular speed

\section{Conclusion}

A differential equation is drawn, which characterizes the interaction of the conic-helical loosener with the fertilizer, and its complete solution has been found. It shows the analytical dependence of the displacement of fertilizer elementary volume on the most important design and technological parameters. It is established that helix angle $\alpha$ has the greatest influence - its twofold increase leads to decrease in displacement by 2,3 times. The second most important factor is the influence of angular speed of the loosener. Its twofold increase leads to decrease in displacement by $30 \%$ which is due to the bigger slipping of material particle (elementary volume) and increase of its relative motion. The overall study of the graphs of dependence of displacement of elementary volume on variable factors such as the helix angle, the generant angle, the angular velocity of the loosener, the radius of position of particle (elementary volume) on the conical surface can establish their optimal combination which will guarantee effective loosening.

This research was done for the latest loosener construction patented at the Republic of Kazakhstan.

The presented methodology may be useful both for scientific workers and constructors (designers).

\section{References}

[1] Alferov, P. V. Hoppers, valves and feeders. Principles of design and calculation. Moscow: Mashgiz, 1946. (in Russian)

[2] Koshanov, O. M. Development of a device to prevent stagnant areas in hoppers and arches of hard-running agricultural materials and justification of its parameters and operating modes. Ph. D. Thesis. Ryazan, Russia, 1987. (in Russian)

[3] Tarasov, A. G. Researching vibration arch breaking of feeding stuff in hoppers at poultry farms. Ph. D. Thesis. Saratov, Russia, 1976. (in Russian)

[4] Ternovoy, D. A.; Bogomyagkih, V. A. Engineering design methodology of arch breaking devices of seed drills. // Scientific and Technological Developments in Agriculture. 10, (2000), pp. 20-23.

[5] Pobedinskii, P. N. et al. Methods of assessing the quality of mineral fertilizers application. // Engineering in Agriculture. 4(1988), p. 48

[6] Nukeshev, S. O. Machine for subsurface mineral fertilizers application and tillage. // Bulletin of Science of S. Seifullin KazSATU. 42, 2(2006), pp. 229-235.

[7] Nukeshev, S. O. Cultivator with fertilizer for subsurface variable rate application of mineral fertilizers. // Kazakhstan Science News, Almaty. 3(2006), pp. 183-187.

[8] Nukeshev, S. O.; Lichman, G. I. Selection and justification of parameters of dosing systems of variable rate mineral fertilizer application machines. // Proceedings of the Int. Scientific and Practical Internet Conference "Major problems and perspectives for the development of scientific research, 2008" / KazNAU, Almaty, Kazakhstan, 2008, pp. 222-225.

[9] Patent 19008 RK. Seeding device / Nukeshev S. O., published 15.12.2010, bulletin 12, p. 4: figure.

[10] Nukeshev, S. O. Results of theoretical research of conichelical agitator. Topical problems of modern times. // International Scientific Journal. Series "Engineering", Publisher: Bolashak-Baspa, Karaganda, Kazakhstan, 35, 1(2009), pp. 63-65. 
[11] Kolev, D.; Nenov, S. Mathematics 2 in examples and problems. Academic Publication, Sofia, Bulgaria, 2012.

[12] Kolev, D. Applied algebra and analytic geometry. UCTM, Sofia, Bulgaria, 2012.

[13] Rustembaev, B. E.; Abdirov, A. M.; Nukeshev S.O. Theoretical background for determination of parameters of spring-screw agitator. // Bulletin of Agricultural Science of Kazakhstan, Bastau, Almaty, Kazakhstan. 4(1999), pp. 127130.

\section{Authors' addresses}

Sayakhat Nukeshev, Prof. Ph.D.

S. Seyfullin Kazakh Agro Technical University

62 Zhenis Ave. Astana 100011, Kazakhstan

snukeshev@mail.ru

Dzhadyger Eskhozhin, Prof. Ph.D.

S. Seyfullin Kazakh Agro Technical University

62 Zhenis Ave. Astana 100011, Kazakhstan

edzkz@yahoo.com

Dimitar Karaivanov, Prof. Ph.D.

University of Chemical Technology and Metallurgy

8 Kliment Ohridski Blvd., Sofia 1756, Bulgaria

dipekabg@yahoo.com

Kairat Eskhozhin, Prof. Ph.D.

S. Seyfullin Kazakh Agro Technical University

62 Zhenis Ave. Astana 100011, Kazakhstan

5180664.kz@mail.ru

Aigul Balabekova, M.Sc.

S. Seyfullin Kazakh Agro Technical University 62 Zhenis Ave. Astana 100011, Kazakhstan

algul_balabekova@mail.ru

Ziada Zhaksylykova, M.Sc.

S. Seyfullin Kazakh Agro Technical University

62 Zhenis Ave. Astana 100011, Kazakhstan

ziyada.sapargalieva@mail.ru

Yevgeniy Zolotukhin, M.Sc.

S. Seyfullin Kazakh Agro Technical University

62 Zhenis Ave. Astana 100011, Kazakhstan

zolotukhine17@mail.ru 